\title{
Caracterización Anatómica de la Madera de Cinco Especies Comerciales del Sector la Colonia Simón Bolívar, Cantón Santa Clara, Provincia de Pastaza
}

\author{
Bryan Salinas, \\ Carlos Carpio, \\ Eduardo Salazar, \\ Vilma Noboa, \\ Manuel Espinoza, \\ Daniel Román, \\ Escuela Superior Politécnica de Chimborazo, \\ Facultad de Recursos Naturales, Escuela de Ingeniería Forestal
}

Doi: 10.19044/esj.2019.v15n18p255 URL:http://dx.doi.org/10.19044/esj.2019.v15n18p255

\section{Resumen}

La presente investigación propone la caracterización anatómica de la madera de cinco especies comerciales: Inga edulis Mart., Miconia rivalis Wurdack, Piptadenia flava (Spreng. ex DC.) Benth, Piptocoma discolor (Kunth) Pruski, Syzyguium jambos (L.) Alston, del Sector la colonia Simón Bolívar, cantón Santa Clara, provincia de Pastaza; para lo cual se tomaron muestras dendrológicas y probetas de madera de cada especie que fueron identificadas en el herbario de la Escuela Superior Politécnica de Chimborazo (CHEP). Para la descripción de las características macroscópicas de las maderas estas fueron previamente secadas durante 30 días y se utilizaron para la determinación de características como textura, lustre, sabor, olor, veteado, grano y color, mientras que para las características microscópicas se obtuvieron cubos de $2 \mathrm{~cm}$ por arista, ablandados en autoclave y con agua destilada en diferentes ciclos dependiendo de cada especie. Posteriormente se utilizó un micrótomo para realizar cortes de los distintos planos de los cubos de madera; estas láminas fueron colocadas en cajas Petri con los distintos tintes (Verde brillante, Orceína (A y B)). Se realizó la observación en el microscopio y se determinaron los tipos de poros en los tres tintes, el tamaño y número de poros por especie.

Palabras clave: Características macroscópicas y microscópicas, Fibras, Tejidos vegetales, Poros, Tintes 


\title{
Anatomical Characterization of the Wood of Five Commercial Species of the Sector Colonia Simón Bolívar, Cantón Santa Clara, Province of Pastaza
}

\author{
Bryan Salinas, \\ Carlos Carpio, \\ Eduardo Salazar, \\ Vilma Noboa, \\ Manuel Espinoza, \\ Daniel Román, \\ Escuela Superior Politécnica de Chimborazo, \\ Facultad de Recursos Naturales, Escuela de Ingeniería Forestal
}

\begin{abstract}
This paper proposes the anatomical characterization of the wood of five commercial species: Inga edulis Mart., Miconia rivalis Wurdack, Piptadenia flava (Spreng. ex DC.) Benth, Piptocoma discolor (Kunth) Pruski, and Syzyguium jambos (L.) Alston from Simon Bolivar Sector, Santa Clara Canton, and Pastaza Province. In order to perform this study, dendrologic and wood test tubes was taken from each species. To identify those species, some dendrologic samples in Escuela Superior Politecnica de Chimborazo's herbal (CHEP) were collected. For the description of the macroscopic characteristics of the woods, they were previously dried for 30 days and were used for determining characteristics such as texture, luster, taste, odor, marbled wood, grain, and color. For the microscopic characteristics, cubes were obtained $2 \mathrm{~cm}$ per edge, softened in autoclave and with distilled water in different cycles depending on each species. Subsequently a microtome was used to make cuts of the different planes of the wooden cubes. These plates were placed in Petri dishes with different dyes (Bright green, Orcein (A and B)). The observation was made under the microscope and the pore types were determined in the three dyes, the size, and number of pores per species.
\end{abstract}

Keywords: Macroscopic and microscopic characteristics, Fibers, Plant Tissues, Pores, Dyes 


\section{Introduction}

La sostenibilidad ha sido un tema popular en los últimos años, y la aplicación de este concepto en la silvicultura debe considerar una asociación estrecha entre la conservación de la naturaleza y la gestión forestal basada en la tecnología, así como las consideraciones económicas y sociales (Pereira et al., 2014).

A pesar de los muchos usos humanos que el hombre ha dado a las maderas, a un nivel fundamental, la madera es una estructura biológica compleja, compuesta de muchos compuestos químicos y tipos de células que actúan conjuntamente para satisfacer las necesidades de la planta (Wiedenhoeft \& Miller, 2005). La madera realiza tres funciones críticas: soporte mecánico de la superficie fotosintética (Rowe \& Speck, 2005); almacenamiento de agua, azúcar y otros nutrientes (Sauter \& van Cleve, 1994); y la conducción de agua y otras sustancias desde el suelo a la superficie fotosintética (Sperry, 2003).

La comprensión de los requisitos básicos dictados por estas tres funciones y la identificación de las estructuras en madera que las realizan permiten conocer el ámbito del uso de la madera humana (Hoadley 2000).

Los resultados en la anatomía de la madera de un gran número de especies leñosas podrían interpretarse enfáticamente como que la gran variación en los rasgos anatómicos de la madera mencionada anteriormente podría utilizarse en la delimitación taxonómica de las especies, así como en la determinación de la calidad de la madera y su utilidad (Rodriguez et al., 2016).

En este sentido, el presente estudio procura conocer y analizar las características anatómicas de cinco especies comerciales del Oriente Inga edulis Mart.,, Miconia rivalis Wurdack Piptadenia flava (Spreng. ex DC.) Benth, Piptocoma discolor (Kunth) Pruski, Syzyguium jambos (L.) Alston, con la finalidad de ofrecer información para un mejor uso de la madera para el aprovechamiento forestal de maderas, además de proveer información que será básica para futuras investigaciones en Ecuador.

\section{A. Metodología}

El presente trabajo de investigación se llevó a cabo en la Colonia Simón Bolívar, Cantón Santa Clara, Provincia de Pastaza. Latitud: $1{ }^{\circ} 27^{\prime}$ 59.9024" S Longitud: 77 58' 59.9860" W (Figura 1). Las metodologías aplicadas se basan en las normas de la Comisión Panamericana de Normas Técnicas (COPANT). Adicionalmente se trabajó con los permisos respectivos de recolección solicitados por el Ministerio del Ambiente. 


\section{Descripción Dendrológica}

Se tomaron muestras representativas de cada una de las 5 especies en estudio; se georreferenció cada uno de los árboles en estudio con la ayuda de un GPS (Garmin, Gpsmap 64s, Kansas, EEUU). Las muestras fueron llevadas al herbario de la Escuela Superior Politécnica de Chimborazo (CHEP), en donde se procedió al análisis de las muestras.

\section{Análisis de las características macroscópicas de las muestras 2.1 Dimensión de las muestras}

De un corte circular o transversal de las ramas recolectadas se dimensionó una probeta de madera por cada especie de 15 × 9 × $2 \mathrm{~cm}$ aproximadamente.

\subsection{Acondicionamiento de las muestras}

Se realizó el proceso de secado de las probetas a temperatura ambiente durante 30 días.

\subsection{Determinación de características organolépticas}

Para la descripción de las características perceptibles por los sentidos (organolépticas) se utilizó la tabla Munsell para definir el color de cada una de la muestras.

Para las características como brillo o lustre se catalogó como bajo, medio y alto. La textura como: gruesa, media y fina; el veteado se catalogó en: jaspeados satinados y arcos superpuestos; el olor se catalogó como: dulce, aromático, fragante y finalmente el sabor en: agradable o desagradable, dulce, picante amargo y agrio.

Para facilidad de reconocimientos de estas características se realizaron cortes pequeños de las probetas con la ayuda de un estilete; adicionalmente se utilizó una lupa de 10x para facilitar la observación y descripción.

\section{Análisis de las Características microscópicas de las muestras}

Para el análisis de las características microscópicas de las muestras de madera por cada especie se realizaron pequeños cortes de trozos cúbicos extraídos de cada una de las probetas, de $2 \mathrm{~cm}$ de arista por cada muestra, los cuales fueron ablandados con un autoclave vertical de 30x60 (TETSAKA, TV3C, Queretaro, México). Estos trozos se introdujeron en envases de plástico con $250 \mathrm{ml}$ de agua destilada sellados con papel aluminio, con una presión de $0,15 \mathrm{MPa}$, a una temperatura de $121{ }^{\circ} \mathrm{C}$ mediante ciclos de una hora dependiendo del tipo de madera de cada especie.

Con el micrótomo rotatorio se realizó el corte de las láminas correspondientes a tres secciones (transversal, tangencial y radial) de 0,3 micras, las cuales se colocaron en cajas Petri con sus respectivas etiquetas. 
Para la coloración e inmersión de las láminas se prepararon los tintes (Tabla 1).

Tabla 1. Detalle de los tintes utilizados en la caracterización anatómica

\begin{tabular}{|l|l|l|l|l|}
\hline \multicolumn{1}{|c|}{ Tinte } & \multicolumn{1}{c|}{ Cantidad $(\mathbf{g})$} & \multicolumn{1}{c|}{ Reactivos } & \multicolumn{1}{c|}{ Cantidad (ml) } & \multicolumn{1}{c|}{ Agua destilada (ml) } \\
\hline Orceína A & 0,5 & Acético + ácido clorhídrico & $22,9+4,15$ & 22,9 \\
\hline Orceína B & 0,45 & Ácido Acético & 27,5 & 27,5 \\
\hline $\begin{array}{l}\text { Verde } \\
\text { Brillante }\end{array}$ & 12,5 & Alcohol + ácido fosfórico & $6,25+12,5$ & 31,25 \\
\hline
\end{tabular}

Para la tinción de las láminas se realiza una inmersión de 30 a 40 segundos por cada colorante, en las distintas cajas Petri con ayuda de la pinza de metal. Estas láminas preparadas se colocaron en un portaobjetos y cubre objetos con la ayuda de la pinza de metal para ser selladas luego con esmalte transparente con el fin de mejorar el estado de conservación de las placas.

Finalmente se observaron en el microscopio (Quilmes motic, China) con lentes de 10x y 40x las secciones transversales, radiales y tangenciales de cada una de las muestras, las cuales fueron observadas con una cámara de 5 mega pixeles en el programa Toup View.

\section{Análisis de Imágenes}

Para el análisis de las imágenes se utilizó la cámara An Scope incorporada al software Toup View 3,7 instalada en el microscopio. Se utilizó el programa Motic Images Plus 2.0 ML (CHINA GROPUP Co., Ltd., China), para la medición de poros en micrómetros (um).

\section{Análisis Estadístico}

Se trabajó con cuatro repeticiones por cada especie, para los cortes trasversal, radial y tangencial. Se analizó el perímetro y número de poros. Se verificó la normalidad para lo que se aplicó la prueba de Shapiro - Wilks. Comprobada la normalidad se aplicó un ANOVA y para conocer la diferencia entre los tratamientos se aplicó la prueba de TUKEY al $5 \%$. En el caso donde los datos no fueron normales se aplicó la prueba no paramétrica de Krukal Wallis. Para el análisis estadístico se aplicó el programa Infostat.

\section{a) Análisis de los poros}

Se observó: número de poros simples, múltiples de dos y múltiples de tres de las placas de la sección transversal en cada tinte de cada una de las especies en estudio. Se trabajó con capturas fotográficas con un lente de 4X.

\section{b) Número de Poros}

Se observó una placa de la sección transversal de cada especie, en la cual se delimitó un área de $1 \mathrm{~cm}$ por $1 \mathrm{~cm}$ para posteriormente colocar la placas 
en observación del microscopio en un lente de 40X y capturar campos ópticos para el conteo de poros.

\section{c) Análisis de Perímetros}

Se tomó en consideración la mejor tinción y la observación del lente en 10x mediante un análisis de varianza a través de la Prueba de Kruskal Wallis en el programa estadístico Infosat.

\section{Cálculo de Densidad}

Se pesaron individualente 4 trozos cúbicos de $2 \mathrm{~cm}$ de arista aproximadamente por cada especie en estudio en una balanza analítica (Mettler Toledo, MS-TS, Ohio, EEUU) de 0,01 gramos de precisión; con un pie de rey se midieron las tres aristas de cada uno de los 4 cubos de madera de las especies en estudio para poder calcular el volumen. Con los datos de masa y volumen se calcula la densidad de cada una de las muestras.

\section{Resultados}

A continuación se presentan los principales resultados de las observaciones realizadas para las cinco especies estudiadas, en relación con las características dendrológicas (Tabla 2), macroscópicas (Tabla 3), y microscópicas (Tabla 4).

Tabla 2. Principales características dendrológicas de las especies en estudio

\begin{tabular}{|c|c|c|c|}
\hline $\begin{array}{l}\text { Nombre } \\
\text { Científico }\end{array}$ & $\begin{array}{l}\text { Nombre } \\
\text { común }\end{array}$ & Familia & Descripción \\
\hline $\begin{array}{l}\text { Piptocoma } \\
\text { discolor } \\
\text { (Kunth) Pruski }\end{array}$ & $\begin{array}{l}\text { Pigue, } \\
\text { Cenizo }\end{array}$ & Asteraceae & $\begin{array}{l}\text { Árbol de } 18 \text { metros con corteza fisurada } \\
\text { de color café marrón con exudado } \\
\text { ausente, hojas simples elípticas a } \\
\text { ovaladas con filotaxia alterna, flores } \\
\text { con color blanco. }\end{array}$ \\
\hline $\begin{array}{l}\text { Miconia } \\
\text { rivalis } \\
\text { Wurdack }\end{array}$ & $\begin{array}{l}\text { Sangre de } \\
\text { Gallina }\end{array}$ & Melastomataceae & $\begin{array}{l}\text { Árbol de } 6 \mathrm{~m} \text {, corteza lisa café, hojas el } \\
\text { de gran tamaño elípticas, flores blancas }\end{array}$ \\
\hline $\begin{array}{l}\text { Inga edulis } \\
\text { Mart }\end{array}$ & $\begin{array}{l}\text { Guaba, } \\
\text { Guabillo }\end{array}$ & Fabaceae & $\begin{array}{l}\text { Árbol de } 8 \text { metros, corteza externa lisa } \\
\text { de color pardo grisáceo. } \\
\text { compuestas paripinnadas, flores } \\
\text { blancas }\end{array}$ \\
\hline $\begin{array}{c}\text { Piptocoma } \\
\text { flava }(\text { Spreng) } \\
\text { Benth }\end{array}$ & $\begin{array}{l}\text { Fashaco, } \\
\text { Pachaco, } \\
\text { Guarango }\end{array}$ & Fabaceae & $\begin{array}{c}\text { Árbol de } 7 \text { metros, copa muy alargada } \\
\text { abierta corteza grisácea áspera, hojas } \\
\text { compuestas alternas, flores en espiga } \\
\text { color blanco-vinoso }\end{array}$ \\
\hline $\begin{array}{l}\text { Syzygium } \\
\text { jambos } \quad(L .) \\
\text { Alston }\end{array}$ & $\begin{array}{l}\text { Pomarosa, } \\
\text { Pomaroca }\end{array}$ & Myrtaceae & $\begin{array}{l}\text { Árbol de } 16 \text { metros con corteza } \\
\text { grisácea, hojas opuestas lanceoladas, } \\
\text { flores blanco- amarillentas en racimos }\end{array}$ \\
\hline
\end{tabular}


Tabla 3.Características macroscópicas de las especies en estudio

\begin{tabular}{|c|c|c|c|c|c|}
\hline ESPECIE & $\begin{array}{l}\text { Piptocoma } \\
\text { discolor } \\
\text { Pigue }\end{array}$ & $\begin{array}{l}\text { Miconia } \\
\text { rivaldis } \\
\text { Sangre } \\
\text { gallina }\end{array}$ & $\begin{array}{l}\text { Inga densiflora } \\
\text { - Guaba }\end{array}$ & $\begin{array}{l}\text { Piptadenia cf } \\
\text { flava-Pachaco }\end{array}$ & $\begin{array}{l}\text { Syzygium } \\
\text { jambos } \\
\text { Pomarosa }\end{array}$ \\
\hline \multicolumn{6}{|c|}{ CARACTERÍSTICAS } \\
\hline Corteza & $\begin{array}{l}\text { Fisurado de } \\
\text { color Negro }\end{array}$ & $\begin{array}{lr}\text { Lisa } & \text { algo } \\
\text { agrietada } & \text { de } \\
\text { color café } & \end{array}$ & $\begin{array}{l}\text { lisa de color } \\
\text { pardo grisáceo }\end{array}$ & Grisácea áspera & Grisácea \\
\hline Sabor & Ausente & $\begin{array}{l}\text { Ligeramente } \\
\text { amargo }\end{array}$ & Ausente & Amargo & Ausente \\
\hline Olor & $\begin{array}{l}\text { Agradable no } \\
\text { distintivo }\end{array}$ & $\begin{array}{l}\text { Agradable no } \\
\text { distintivo }\end{array}$ & $\begin{array}{l}\text { Agradable no } \\
\text { distintivo }\end{array}$ & $\begin{array}{l}\text { Desagradable } \\
\text { (Olor ajo) }\end{array}$ & $\begin{array}{ll}\text { Agradable no } \\
\text { distintivo }\end{array}$ \\
\hline Lustre & Medio & Medio & Medio & Medio & Medio \\
\hline Grano & Entrecruzado & Ondulado & Entrecruzado & Ondulado & Recto \\
\hline \multirow[t]{2}{*}{ Veteado } & Jaspeado & Jaspeado & Jaspeado & Jaspeado & Arcos \\
\hline & Satinado & Satinado & Satinado & Satinado & Superpuestos \\
\hline Textura & Media & Media & Media & Gruesa & Fina \\
\hline Color & $\begin{array}{l}8 / 2 \text { muy pálido } \\
\text { marrón }(10 \\
\text { YR) }\end{array}$ & $\begin{array}{ll}8 / 2 & \text { Rojizo } \\
(5 \mathrm{R}) & \end{array}$ & $\begin{array}{l}8 / 2 \text { muy pálido } \\
\text { marrón } \quad(10 \\
\text { YR) }\end{array}$ & $\begin{array}{l}8,5 / 2 \text { muy } \\
\text { pálido marrón } \\
(10 \mathrm{YR})\end{array}$ & $\begin{array}{l}\text { 7/3 muy pálido } \\
\text { marrón } \\
\text { YR) }\end{array}$ \\
\hline
\end{tabular}

Tabla 4. Características microscópicas de las especies en estudio

\begin{tabular}{|c|c|c|c|c|c|}
\hline Especies & Poros & Parénquima & $\begin{array}{l}\text { Tamaño de } \\
\text { poros }\end{array}$ & & Densidad \\
\hline $\begin{array}{l}\text { Piptocoma } \\
\text { discolor }\end{array}$ & $\begin{array}{l}\text { Poros solitarios, } \\
\text { escasos múltiples } \\
\text { radiales de dos y } \\
\text { múltiples de tres. }\end{array}$ & $\begin{array}{l}\text { Axial } \\
\text { apotraqueal } \\
\text { difuso }\end{array}$ & $\begin{array}{l}\text { Mediano tamaño } \\
\text { en poros } \\
\text { solitarios y poros } \\
\text { múltiples. }\end{array}$ & Difuso & 0,407 \\
\hline $\begin{array}{l}\text { Miconia } \\
\text { rivalis }\end{array}$ & $\begin{array}{l}\text { Poros solitarios, } \\
\text { escasos múltiples } \\
\text { radiales de dos }\end{array}$ & $\begin{array}{l}\text { Apotraqueal } \\
\text { difuso }\end{array}$ & $\begin{array}{l}\text { Mediano tamaño } \\
\text { en poros } \\
\text { solitarios y poros } \\
\text { múltiples. }\end{array}$ & Difuso & 0,613 \\
\hline Inga edulis & $\begin{array}{l}\text { Poros solitarios, } \\
\text { escasos múltiples } \\
\text { radiales de dos }\end{array}$ & $\begin{array}{l}\text { Apotraqueal } \\
\text { difuso }\end{array}$ & \begin{tabular}{lr}
\multicolumn{2}{l}{ Pequeño tamaño } \\
de Poros & en \\
solitarios & y \\
múltiples.
\end{tabular} & Difuso & 0,431 \\
\hline $\begin{array}{l}\text { Piptadenia } \\
\text { cf flava }\end{array}$ & $\begin{array}{l}\text { Poros solitarios, } \\
\text { escasos múltiples } \\
\text { radiales de dos }\end{array}$ & $\begin{array}{l}\text { Paratraqueal } \\
\text { aliforme }\end{array}$ & $\begin{array}{l}\text { Gran tamaño en } \\
\text { poros solitarios y } \\
\text { mediano en poros } \\
\text { múltiples }\end{array}$ & Difuso & 0,567 \\
\hline $\begin{array}{l}\text { Syzygium } \\
\text { jambos }\end{array}$ & $\begin{array}{l}\text { Poros solitarios, } \\
\text { escasos múltiples } \\
\text { radiales de dos y } \\
\text { múltiples de tres. }\end{array}$ & $\begin{array}{l}\text { Apotraqueal } \\
\text { en bandas }\end{array}$ & $\begin{array}{lr}\text { Pequeño tamaño } \\
\text { de Poros } & \text { en } \\
\text { solitarios } & \text { y } \\
\text { múltiples. }\end{array}$ & Difuso & 0,786 \\
\hline
\end{tabular}




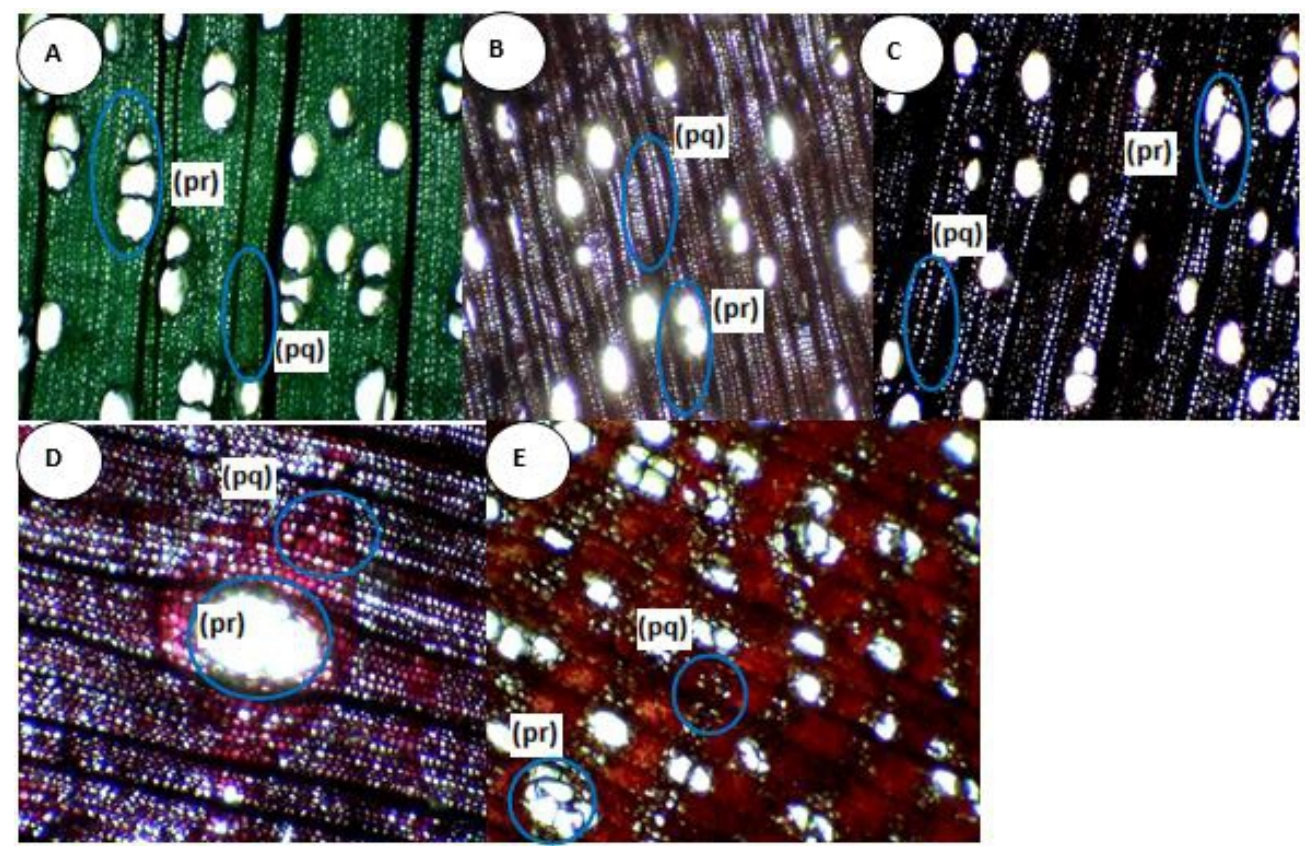

Figura 1. Vista anatómica en un corte trasversal de la madera en un lente de $4 \mathrm{x}$ donde se muestran principalmente los poros y parénquima en las especies: A. Piptocoma discolor, B. Miconia rivaldis, C. Inga edulis, D. Piptadenia Sprenth flava - (Spreng. ex DC.) Benth, E. Syzyguium jambos. Los círculos indican el parénquima (pq) y los poros (pr) en la madera 


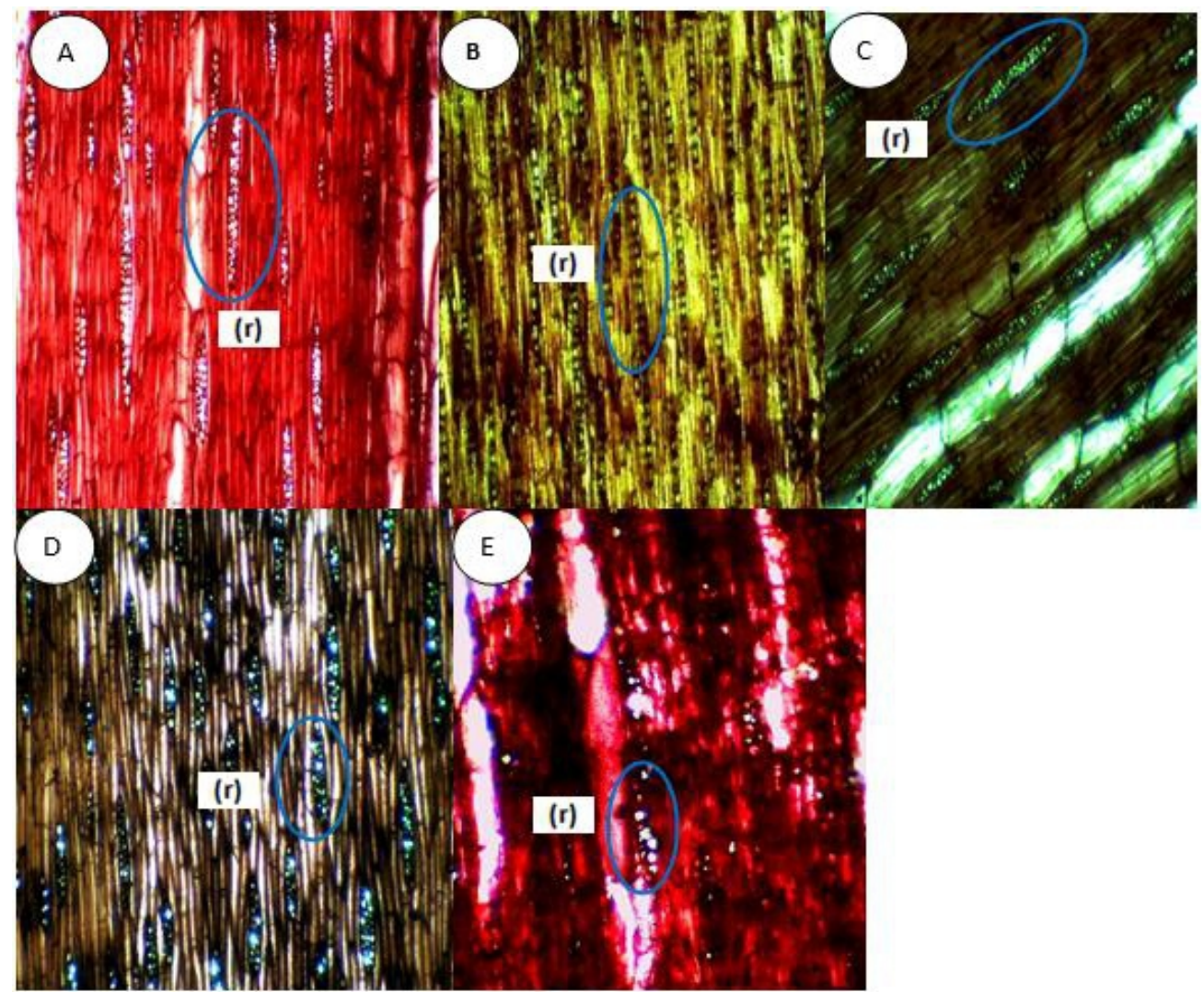

Figura 2. Vista anatómica en un corte tangencial de la madera con un lente 4x donde se muestran principalmente los radios en las especies A. Piptocoma discolor, B. Miconia rivaldis, C. Inga edulis, D. Piptadenia flava - (Spreng. ex DC.) Benth, E. Syzyguium jambos. . Los círculos indican los radios (r) y los poros (pr) en la madera. 

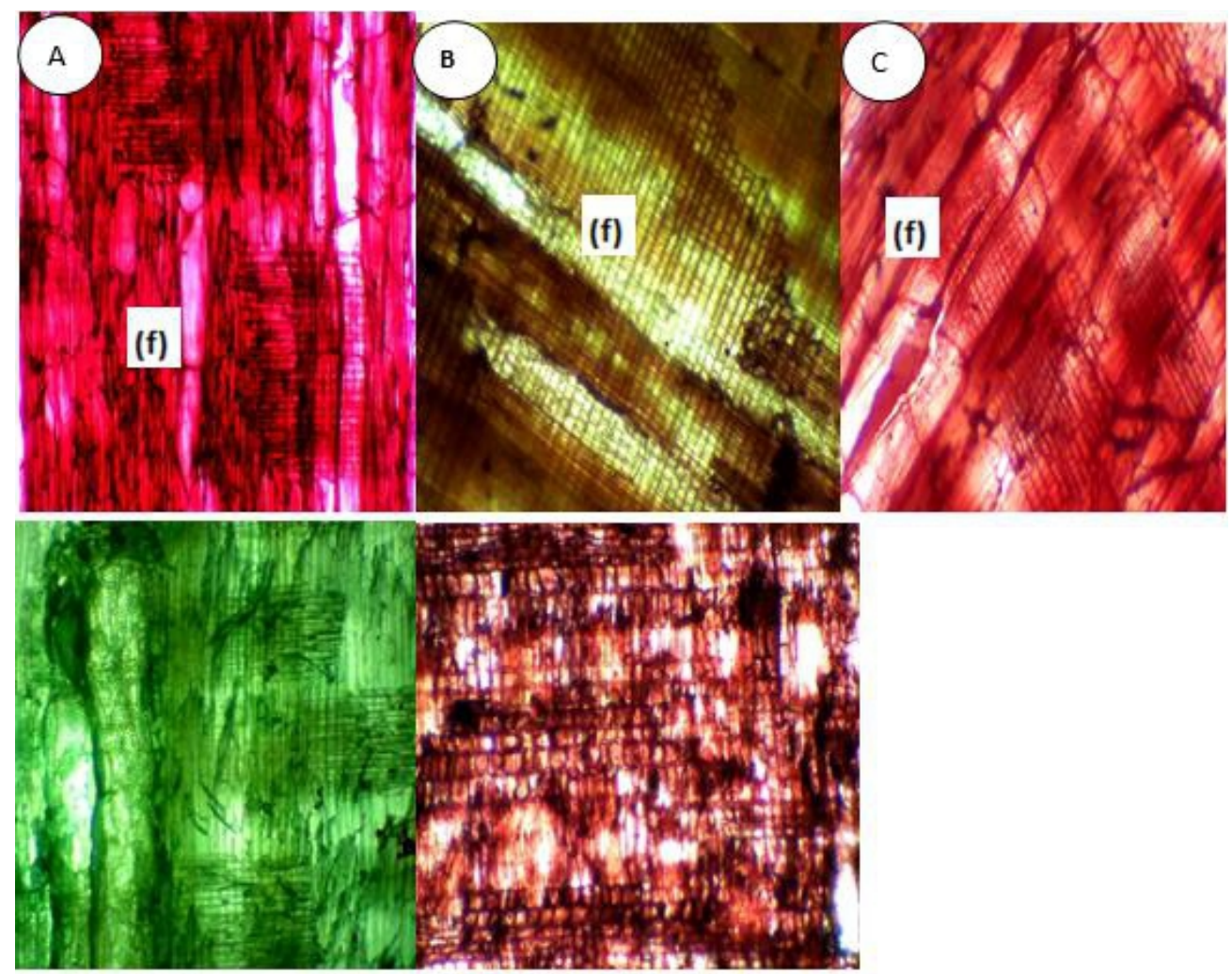

Figura 3. Vista anatómica en un corte radial de la madera con un lente 4x donde se muestran principalmente los radios en las especies A. Piptocoma discolor, B. Miconia rivaldis, C. Inga edulis. D. Piptadenia flava - (Spreng. ex DC.) Benth, E. Syzyguium jambos. . Los círculos indican las fibras (f) en la madera.

\section{Discusión}

\section{Piptocoma discolor ( Kunth) Pruski (Pigue)}

Según estudios realizados con características dendrológicas en Piptocoma discolor ( Kunth) Pruski (pigue) Morejón (2018) afirma que es un árbol de hasta $20 \mathrm{~m}$ de altura; con una corteza fuertemente fisurada, hojas helicoidales membranáceas, verdes por arriba y homogéneamente pardas por el envés con flores pequeñas blanquecinas, con cáliz y corola presentes, el cáliz de 1- $2 \mathrm{~mm}$ de longitud, con características reproductivas con inflorescencia en panículas de cabezuelas con cáliz de color verde y frutos en aquenios color crema (Ministerio del Medio Ambiente del Ecuador; Organización de Naciones Unidas, 2014).

En cuanto a las características macroscópicas (Puchaicela, 2013) afirma que Piptocoma discolor (Kunth) Pruski posee el grano recto, de sabor y olor ausentes; la figura en plano tangencial son arcos superpuestos y en plano radial satinado lo cual se observa en los resultados obtenidos de la investigación. 
A nivel de las características microscópicas se encontró que Piptocoma discolor ( Kunth) Pruski (pigue), comparte ciertas similitudes con las encontradas en estudios realizados en la misma especie según elMinisterio del Medio Ambiente del Ecuador; la Organización de Naciones Unidas, (2014)determina tipos de poros grandes aislados o radiales de 2 a 4 poros, con porosidad difusa con parénquima Apotraqueal; a menudo se presenta parénquima paratraqueal.

\section{Miconia rivalis Wurdack (Sangre de gallina)}

En el presente estudio se encontraron descripciones del árbol Miconia Clavescens,; al mismo tiempo que Slanis \& Goldenberg (2011), comparte ciertas características con Miconia rivallis Wurdack perteneciente al mismo género y el cual describe a un árbol de quince metros de alto, copa en forma de, posee grandes hojas (hasta de medio metro de largo) de forma entre ovalada y elíptica, opuestas, y minúsculas flores con racimos terminales que pueden ser blancas o rosadas. Aguilar \& Castro (2006), también afirma que el género Miconia son arbustos o árboles de (3-6) m de altura, con flores blanco-rosadas, fruto rojizo-verde o morado, perennifolio.

En otro estudio de características macroscópicas según Pulido \& Tapia (2007), en Miconia ferruginea esta posee un color 10 YR 7/3, con olor ausente y con sabor no distintivo, veteado medio, textura fina, grano fino. Frente a los resultados obtenidos presentan lustre medio, con veteado jaspeado satinado, grano recto con una textura media y según la tabla de Munsell 8/2 rojizo (5 YR).

En cuanto a las características microscópicas se encontró que Miconia rivaldis Wurdack comparte algunas características con otra investigación realizada en Miconia glaberrima (Schltdl.) Naudin por el Ministerio del Medio Ambiente del Ecuador; Organización de Naciones Unidas (2014); puesto que pertenecen al mismo género presenta porosidad difusa, principalmente solitarios y múltiples radiales de 2 a 4 , aunque difieren en cuanto al parénquima de axial vasicéntrico escaso y apotraqueal difuso con series de 2 a 3 células.

\section{Inga edulis Mart (Guaba)}

En el presente estudio a nivel de descripción dendrológica se encontró que Inga edulis Mart comparte ciertas similitudes con otra investigación realizada con Inga spuria Humb. \& Bonpl. ex Willd; al pertenecer al mismo género describe a un árbol de 10 (4-20) m de altura, copa amplia; hojas alternas con raquis alado, con 5 a 7 pares de hojuelas oblongas; flores blancas en cabezuelas de corola blanquecina, perfumadas, sésiles, agrupadas en el ápice del raquis.; fruto pubescente perennifolio (Sousa, 1993). 
En un estudio de características macroscópicas se encontró que Inga alba $\mathrm{Sw}$ Wild comparte algunas características similares a Inga edulis Mart ya que pertenecen al mismo género ; en cuanto al sabor y olor no son distintivos, lustre mediano, grano recto a inclinado, textura mediana con madera de color crema rosáceo sin transición albura duramen (León, 2008).

En cuanto a las características microscópicas se verificó que Inga edulis Mart presenta una porosidad difusa, vasos de contorno circular, principalmente solitarios y escasos múltiples radiales de 2 o 3, fibras con punteaduras opuestas, parénquima axial paratraqueal aliforme y aliforme confluente, apotraqueal escaso, con series de 2 a 3 células (Ministerio del Medio Ambiente del Ecuador; Organización de Naciones Unidas, 2014).

\section{Piptadenia flava ( Spreng) Benth (Fachaco)}

La Piptadenia leptocarpa Rose, al ser del mismo género que Piptademia flava (Spreng) Benth, comparte ciertas características de descripción como que es un árbol de 12 a 16 metros de altura con fuste cilíndrico de copa amplia, corteza áspera grisácea en árboles con hojas compuestas, alternas, flores en espiga color blanco (Milliken, Klitgard, \& Baracat, 2009).

En cuanto a las características macroscópicas se encontró que Piptademia flava ( Spreng) Benth posee ciertas similitudes con otra investigación realizada en Piptadenia cateniformis Ducke en cuanto al color castaño amarillento y no hay transición entre albura y duramen, olor ausente, el brillo es medio, el sabor es ausente, el grano es oblicuo y la textura es media. (Ministerio del Medio Ambiente del Ecuador; Organización de Naciones Unidas, 2014).

A nivel de las características microscópicas se encontró que Piptademia flava (Spreng) Benth comparte ciertas similitudes con otra investigación realizada en Piptadenia cateniformis Ducke, por parte del Ministerio del Medio Ambiente del Ecuador; Organización de Naciones Unidas (2014), puesto que pertenecen al mismo género, en su mayoría presentan algunas características similares en cuanto a los poros en su mayoría solitarios y en menor proporción agrupados en radiales cortos, en hileras radiales $y / u$ oblicuas ; en cuanto al parénquima de forma es de tipo aliforme frente.

\section{Syzygium jambos (L.) Alston (Pomarrosa)}

En un estudio realizado por Francis (1995) este afirma que Syzygium jambos (L.) Alston es un árbol mediano, mide de 10 a $16 \mathrm{~m}$ de altura, tiene hojas que al macerarlas despiden un olor aromático, hojas opuestas, lanceoladas, muy acuminadas con flores; estas son aromáticas y con numerosos estambres largos de color blanco amarillento-amarillo con frutos 
que son drupas de color amarillo claro o rosado; la pula es firme, jugosa y muy aromática, similar a los resultados obtenidos en la investigación.

En estudios realizados con referencias características macroscópicas en la madera se encontró un estudio en Psidium sartorianum, el cual al ser perteneciente a la familia Myrtaceae posee ciertas similitudes con Syzygium jambos (L.) Alston en cuanto al olor que no es característico, el sabor amargo, el brillo medio y el veteado pronunciado en arcos superpuestos, textura fina e hilo recto (Rebollar, Quintanar \& Perez, 1994).

En un estudio de estructura microscópica en dos especies pertenecientes a la misma familia Mytaceae, Eugenia mayana Standley y Eugenia schiedeana Schlecht presentan características similares a Syzygium jambos (L.) Alston en cuanto a porosidad difusa; la mayoría de los poros son solitarios, de contorno oval o circular y algunos múltiples radiales, muy numerosos, de diámetro moderadamente pequeño, pero difieren en cuanto al parénquima de tipo axial el cual es en bandas de 2 a 4 hileras de células y difuso (Dominguez \& Tapia, 2009).

\section{Conclusiones}

1. El presente estudio nos permitió identificar dendrológicamente a cinco especies forestales que son comercialmente importantes en nuestro país. La anatomía de la madera nos permite determinar las especies forestales y sus componentes microscópicos y organolépticos que nos ayuden a hacer una correcta utilización en la industrialización de la madera, así como también su posible comercialización en algunos sectores interesados en estas especies. La afinidad que poseen los tintes en estudio nos muestra la gran variabilidad y diversidad de especies que poseemos; los tintes utilizados permitieron visualizar con gran claridad las estructuras anatómicas de la madera en los cortes tangencial, radial y transversal.

2. Se observaron las características microscópicas de la madera de las especies en estudio tomando en cuenta tres colorantes; en corte trasversal se determinó que tuvo una excelente afinidad para todas las especies en todas las especies; en los cortes tangencial y radial para todas las especies tuvo una mayor adaptabilidad para visualización con Orceínas A y B, a diferencia del colorante verde brillante del cual no se obtuvo una excelente observación.

3. De las cinco especies en estudio se obtuvo variabilidad en cuanto al tamaño, número de poros por placa y densidad, observándose que las especies con poros más pequeños resultaron con mayor número de poros por placa y densidad más alta; en el caso de las especies de mayor tamaño de poros se obtuvo un menor número de poros por placa con densidad más baja. 


\section{References:}

1. Aguilar, R. (2008). Perfil de maderas y elaborados. Quito: Publicaciones CICO.

2. Dominguez, S. \& Tapia, N. (2009). Anatomía de la madera de dos especies de Eugenia (Myrtaceae) de Quintana Roo, México. Madera y bosques, 16(1), 85-98.

3. Francis, J. (1995). Syzygium jambos (L.) Alst. Rose apple. New Orleans: Department of Agriculture, Forest Service, Southern Forest Experiment Station, Institute of Tropical Forestry; . 4 p. (SO-ITF-SM; 26).

4. Hoadley, R.B. (2000). Understanding wood: a craftsman's guide to wood technology. Taunton press.

5. León, W. (2008). Anatomía de la madera en 32 especies de la subfamilia mimosoideae ( leguminoseae) en Venezuela. Revista Colombiana Forestal , 18(24), 15-16.

6. Milliken, W., Klitgard, B. \& Baracat, A. (2009). Clave interactiva y recursos de información para plantas florecientes de los Neotropico. México.

7. Ministerio del Medio Ambiente del Ecuador; Organización de Naciones Unidas (2014). Organización Propiedades anatómicas, físicas y mecánicas de 93 especies forestales - Ecuador. Quito: Tallpa Publicidad Impresa.

8. Morejón, C. (2018). Determinación de las propiedades físicas y mecánicas de tres especies forestales: piptocoma discolor (Kunth.) pruski (pigue), iriartea deltoidea ruiz \& pav.(Chonta) y pouteria glomerata (Intachi). (Tesis de grado. Ingeniero Forestal). Escuela Superior Politécnica de Chimborazo. Riobamba.

9. Pereira Gonçalves, T. A., Wagner Ballarin, A., Nisgoski, S. \& Bolzon de Muñiz, G. I. (2014). A contribution to the identification of charcoal origin in Brazil: I-anatomical characterization of corymbia and eucalyptus. Maderas. Ciencia y tecnología, 16(3), 323-336.

10. Puchaicela, C. (2013). Estudio de la estructura anatómica y propiedades físico-mecánicas de cinco especies maderables en bosques secundarios del cantón. Loja: Universidad Nacional de Loja.

11. Pulido, D. \& Tapia, C. (2007). Descripción anatómica de la madera de cuarenta especies del bosque alto- andino en Guasca, Cundinamarca. Revista Colombia Forestal. 10(20), 25.

12. Rebollar, S., Quintanar, A. \& Perez, C. (1994). Estudio Anatómico de la madera de Psidium sartorianum (Mytaceae y Cordia gerascanthus (Boraginaceae). Acta Botánica Mexicana, (27), 89-97.

13. Rodriguez, H. G., Maiti, R. \& Kumari, A. (2016). Research Advances on Leaf and Wood Anatomy of Woody Species of aTamaulipan Thorn 
Scrub Forest and its Significance in Taxonomy and Drought Resistance. Forest Research, 5(183), 2.

14. Rowe, N. \& Speck, T. (2005). Plant growth forms: an ecological and evolutionary perspective. New phytologist, 166(1), 61-72.

15. Sauter, J.J. \& van Cleve, B. (1994). Storage, mobilization and interrelations of starch, sugars, protein and fat in the ray storage tissue of poplar trees. Trees, 8(6), 297-304.

16. Slanis, A. \& Goldenberg, R. (2011). Notas sobre el género miconia (Melastomataceae) en la Argentina. Darwiniana, 99-103.

17. Sousa, M. (1993). El género Inga (Leguminosae: Mimosoideae) del sur de México y Centroamérica, estudio previo para la Flora Mesoamericana. Annals of the Missouri Botanical Garden, 223-269.

18. Sperry, J.S. (2003). Evolution of water transport and xylem structure. International Journal of Plant Sciences, 164(S3), 115-127.

19. Wiedenhoeft, A.C. \& Miller, R.B. (2005). Structure and function of wood. Handbook of wood chemistry and wood composites, 9-33. 